\title{
OPROCESSO DE ADOÇÃO: CONHECENDO AS VIVÊNCIAS DAS FAMÍLIAS ADOTANTES
}

\author{
Ana Carolina Gravena Vanalli* \\ Andréia Miguel de Santana**

\section{Resumo:} \\ A adoção envolve modificações tanto para o filho quanto para o lar adotivo. Buscando \\ conhecer as experiências relativas à adoção, vivências do casal e da família, foram \\ entrevistadas duas mães adotantes. Os resultados indicam que a integração da criança \\ adotada realizou-se de forma positiva, completando um aparente vazio, sendo a criança \\ adotada considerada responsável pela harmonia familiar.
}

Palavras-chave: Adoção, Família, Criança.

\section{Introdução}

Existem atualmente, de acordo com a Legislação Brasileira, dois tipos de adoção: a adoção prevista no Código Civil - Lei n?10406 de 10 de Janeiro de 2002 e a adoção prevista no Estatuto da Criança e Adolescente - Lein 8069 de 13 de Julho de 1990 (BRASIL, 1990). A primeira é realizada por escritura pública, sendo que para sua efetivação faz-se necessário o comparecimento do adotante e do adotado no Cartório de Registro Civil onde será lavrada a escritura de adoção. Para a efetivação desse tipo de adoção, ambos devem ter a maioridade civil e o adotando deve ter mais de 18 anos (PAIVA, 1997).

No segundo caso, envolvendo crianças e adolescentes, esta é efetivada por intermédio de um processo judicial que tramitará em Varas da Infância e da Juventude. Esta adoção atribui condição de filho ao adotado e não pode ser revogada. Após sua consumação, os nomes dos adotantes constam no registro civil como pais, bem como o nome de seus ascendentes. O registro original da criança ou do adolescente adotado será cancelado (PAIVA, 1997). Para muitos candidatos a adoção, a espera pela chegada de uma criança na família pode alongar-se. Nesses casos, os candidatos trazem consigo critérios de seleção para a criança a ser adotada, como: escolha do sexo, de cor de pele, de cabelo ou de olhos e preferência para que haja grande

*Mestre em Educação Especial, Doutoranda em Psicologia e professora do Centro Universitário de Araraquara - Uniara.

**Psicóloga, formada pelo Centro Universitário de Araraquara - Uniara. 
semelhança física com os pais adotivos. Entretanto, a diferença física entre pais e filhos não prejudica o acolhimento, da mesma forma, a semelhança não garante verdadeira aceitação. Os laços da adoção se fariam por meio da disponibilidade amorosa da criança a família. (MALDONADO, 1995).

Algumas vezes, a falta de informação exclui do processo pessoas que gostariam de ser adotantes e que desconhecem as possibilidades de candidatar-se. Além das condições definidas em lei, existem outros critérios de preferência como: candidatos jovens, de nível socioeconômico elevado, casados, estéreis ou que possuam poucos filhos. (FERREIRA; CARVALHO, 2000).

A adoção se constitui numa forma de restituir a família a muitas crianças que vivem os efeitos do abandono ou que se encontram em situação de abrigo. Deste modo, esta precisa ser pensada de maneira contextualizada, levando em consideração o momento histórico, social e político nos diferentes períodos vividos pela sociedade, sendo imprescindível considerar a influência das diversas culturas e diferentes concepções acerca da constituição familiar e sobre a adoção (PAIVA, 2004).

O processo de adoção envolve modificações tanto para a criança quanto para o novo lar na família com filhos adotivos, é preciso que a criança atravesse a dor de não ter sido acolhida pela família biológica, o que costuma refletir em maior vulnerabilidade aos sentimentos de rejeição e de baixa auto-estima; os pais adotivos precisarão atravessar a dor de não terem gerado aquela criança, e todos precisarão enfrentar as dúvidas sobre as origens, posto que, na maioria dos casos de adoção, não há contato entre a família adotiva e a biológica (MALDONADO, 1995).

A questão da adoção de crianças no Brasil parece simples e fácil de ser resolvida. Afinal, em quase todos os lugares o número de famílias interessadas em adotar uma criança à espera de uma família adotiva é grande. Entretanto, apesar das condições aparentemente favoráveis, há crianças à espera por bastante tempo e possivelmente permanecerão nesta, principalmente se esta não corresponder ao perfil idealizado pela maior parte das famílias (COSTA; CAMPOS, 2003)

Por sua vez, a família adotiva pode sentir receio no início de convivência com a criança muito conturbada por sua dificuldade de adaptação, o que pode deixar os pais adotivos receosos quanto ao estabelecimento da relação afetiva. Já os filhos adotados podem passar por sentimentos de perda. Seus comportamentos defensivos, por vezes, revelam mecanismos de sobrevivência, embora não ofereçam equilíbrio emocional satisfatório (LEVINZON, 2004).

Considerando-se que para a Organização Mundial de Saúde (OMS) a adoção é uma maneira apropriada e completa de recriar redes familiares para a criança que foi privada de sua família (Paiva, 2004), esse estudo buscou, por meio do relato de duas famílias adotantes, refletir sobre as vivências dessas famílias. Para isso, foram abordados aspectos como: motivações para adoção; significado da criança para família adotante; adaptação da criança à família e da família à criança adotada; modificações na família após a adoção e dificuldades e satisfações encontradas nesse processo.

\section{Método}

Participaram duas famílias adotantes de uma cidade de médio porte do interior do Estado de São Paulo. Os dados foram coletados junto às duas mães dessas famílias, por meio de uma entrevista. Essas tinham 38 (M1) e 40(M2) anos, eram casadas, com ensino fundamental incompleto e ensino médio incompleto, respectivamente. Uma das mães era empregada doméstica (M1) e outra (M2) era monitora de uma instituição de assistência às mães e crianças desabrigadas. O esposo de M1 tinha 38 anos e o de M2, aqui denominado tinha 43 anos, sendo o primeiro jardineiro e o segundo auditor fiscal. Percebe-se que as famílias eram provenientes de nível econômico distinto. O primeiro casal tinha um filho de cinco anos, sendo este adotivo e o segundo tinha dois filhos, um biológico de 15 anos e outro adotivo, também de 15 anos.

O Juizado da Vara da Infância e Juventude deste Município possibilitou o contato com os participantes, sendo a partir desse contato, agendado o encontro para realização de uma entrevista. Este instrumento foi desenvolvido pelas autoras do estudo com base na literatura nacional sobre adoção. Esse continha 40 questões abertas e 20 questões fechadas que contemplavam temas como: motivações para adoção, adaptação da família e da criança adotada, modificações na rotina, dificuldades enfrentadas, satisfações em relação à adoção, entre outros temas indicados pela literatura como relevantes.

Para garantir a confiabilidade do instrumento foi realizada a análise semântica e de conteúdo deste, também foi submetido à avaliação da Assistente Sociale Psicóloga Judiciária da Vara da Infância e Juventude desta cidade. Os dados foram avaliados por meio de análise de conteúdo, de forma a conhecer, comparar e discutir as vivências destas duas famílias adotantes.

\section{Resultados e discussão}

Ambasfamíliasentrevistadas realizaramumaúnica adoção, sendoesta aúnica tentativa. Estas entrevistadas passaram pelo processo de adoção em períodos bastante diferentes, a primeira no de 2003 e a segunda no ano de 1991. Isto significa que entre os dois processos transcorreram-se 12 anos. Em relação ao tempo transcorrido durante o processo de adoção, para a família 1 (F1) houve um intervalo de 24 mesese para a família 2 (F2) de 6 meses. Nota-se que o tempo das adoções foi bastante diferente, fato que pode ter se dado devido às mudanças no próprio processo de adoção ou em razão dos prérequisitos impostos pelas famílias.

Dentre as motivações destas famílias para adotar uma criança estão: experiência de 
ser adotada na infância pela própria mãe adotiva, dificuldade de engravidar, vontade de ter filhos e presença de outras adoções na família. Para F1 a iniciativa partiu de M1 e para F2 ambos os pais decidiram-se pela prática.

Em relação ao processo de adoção (M1) relata que o casal sentiu-se apoiado pelos profissionais judiciários, sendo encorajados durante a espera pela criança. A segunda mãe (M2) relatou ter sido avisada pela Maternidade a respeito do nascimento da criança, levando-a imediatamente para casa, não atravessando qualquer processo burocrático, entretanto, ambas as famílias adotaram seus filhos ainda recém-nascidos.

No que diz respeito às preferências pela criança a ser adotada, M1 disse não se importar com o sexo ou cor da criança, M2 demonstrou preocupação quanto ao fillho não ser parecido, dizendo temer comentários a respeito da criança não ser seu filho biológico.

Procurou-se saber como havia sido o processo de adaptação da família à criança. Ambas declararam não ter havido problemas, descrevendo o período como agradávele fortemente esperado. Para elas a adaptação da criança à família ocorreu com grande naturalidade.

Em relação às percepções das mães a respeito das mudanças ocasionadas na família com a chegada do bebê, M1, observou-se que a vida familiar se tornou mais rica após a chegada da criança, reatando-se o diálogo e o carinho entre os pais, situações menos presentes anteriormente à chegada da criança. Para M2 a chegada de seu filho trouxe para a família maior felicidade.

As mães foram questionadas a respeito de seus sentimentos em relação à adoção. Ambas, relataram sentimentos bastante positivos em relação a essa prática. M1 relatou acreditar que outras famílias, com filhos biológicos ou não, devessem adotar crianças, uma vez que a experiência é vista como saudável e feliz para família. M2 relata que sua integração ao filho foi tão grande, que se esquece que ele é adotivo.

O fato de revelar ou não à criança sua adoção e o momento escolhido pelos pais para a revelação pode estar envolvido por medo e insegurança. Desta forma, questionou-se às participantes a respeito da revelação da adoção. Percebe-se que para ambas a decisão de revelar a adoção ao fillho foi algo natural, realizada de forma tranquiila pela família, quando as crianças ainda eram pequenas. Percebe-se que houve aceitação do fato pelas crianças e que as famílias não enfrentaram maiores dificuldades nesse processo. M2 ainda relatou grande afinidade entre os irmãos.

Questionou-se, também, a respeito da relação atual entre pais e filho. Ambas relataram estarem bastante satisfeitas com esse aspecto. Da mesma forma, estas relatam bom relacionamento entre os filhos e os outros familiares.

Por fim, perguntou-se se pudessem recomeçar o percurso se fariam algo diferente. M1 relatou com muito entusiasmoque se sente plenamente satisfeita com as situações vivenciadas. M2 relata-se satisfeita, alegando que o relacionamento familiar é bastante satisfatório,

REVISTA UNIARA, $n .{ }^{0}$ 21/22, 2008/2009 prevendo que esse mesmo tipo de relacionamento será repetido em outros contextos. Também, foi perguntado a elas se algo, que não ocorreu, poderia ter facilitado o processo. Ambas responderam negativamente, mostrando-se satisfeitascom as situações vivenciadas.

\section{Discussão}

Nota-se, por seus relatos, que a experiência de adotar um filho, tanto quando ele é filho único (como para M1), tanto quando há a presença de um filho biológico (como para M2) foi muito significativa e prazerosa para ambas as mães, sendo seus relatos permeados por ternura e felicidade.

Em relação aos objetivos deste estudo, tem-se que como motivações para adoção encontram-se relatos a respeito daimpossibilidade de uma gravidez, o fato de existirem outras adoções na família e até o fato de uma das mães adotantes ter vivido parte de sua infância emum lar para menores.

Quandoé considerado o significado da criança adotada para a família adotante, percebese que, em ambos os casos, a criança teve um significado bastante especial, completando um aparente vazio vivido por ambas as famílias, que vêem as crianças adotadas como contribuintes privilegiadas da felicidade e harmonia familiar. Sendo queM2relata, inclusive, que as relações familiares tomaram-se mais satisfatórias após a chegada da criança.

Em relação à adaptação da família e à criança e vice-versa, as mães relataram que não houve problemas, sendo o ambiente familiar enriquecido com a presença dos filhos, não havendo em nenhum dos casos a ocorrência de modificações significativas ou que pudessem causar transtornos à rotina familiar.

O último objetivo deste estudo visou responder às possíveis dificuldadese satisfações vivenciadas no processo de adoção. Nenhuma das mães relatou dificuldades significativas, entretanto, para ambas as satisfações presentes na adoção e convivência com seus filhos foram intensamente presentes.

Desta forma, por meio da análise dos relatos dessas participantes, nota-se que o processo de adoção de uma criança pode ser algo prazeroso e benéfico para pais, crianças e familiares em geral.

Entretanto, deve-se destacar que este estudo foi realizado com apenas duas mães adotantes, de uma mesma cidade e que passaram por processos de adoção em períodos bastante diferentes. Desta forma, os dados encontrados não podem ser conclusivos no que diz respeito a percepção das famílias adotantes sobre o processo de adoção, sendo bastante limitado. Entretanto, lança um vestígio de como o acolhimento de uma criança em adoção pode ser marcado por intensa satisfação.

Outros estudos abrangendo novos temas, com maior número de participantes e realizados em outras regiões dos pais poderiam ser realizados para que fosse possívelo conhecimento mais consistente a respeito do tema.
O processo de adoção... 


\section{Referências bibliográficas:}

BRASIL, Estatuto da criança e do adolescente. Lei n? 8.069 de 13/07/90. São Paulo. 1990.

FERREIRA, P.R.M; CARVALHO, R.S. Primeiro guia de adoção de crianças e adolescentes do Brasil. São Paulo: Fundação Orsa, 2000.

COSTA, L.F.; CAMPSO, N.M.V.A Avaliação psicossocial no contexto da adoção: vivências das famílias adotantes. Psicologia: Teoria e Pesquisa [online]. v.19, n.3, p. 221-230.2003. Disponível em: <http://www.scielo.br/scielo.php?

script=sci_arttext\&pid=S012-37722003000300004\&Ing=Iso > . Acesso em: 10 jun. 2009.

LEVINZON, GK. Adoção. São Paulo: Casa do Psicólogo, 2004.

MALDONADO, M.T. Os caminhos do coração. São Paulo: Saraiva, 1995.

PAIVA, L.D. Adoção: significados e possibilidades. São Paulo: Casa do Psicólogo, 2004.

O segredo na adoção, 1997. Trabalho de conclusão de curso (Especialização) - Pontifícia Universidade Católica de São Paulo, São Paulo, 1997.

Title:

THE ADOPTION PROCESS: KNOWING THE EXPERIENCE OF ADOPTING FAMILIES.

\section{Abstract:}

Adoption includes changes to both the child and the adoptive home. Seeking to know the experiences regarding adoption, the couple and the family's experiences, two adoptive mothers were interviewed. The results indicate that the integration of the adopted child was carried out in a positive way, filling an apparent empty spot, and the adopted child was considered responsible for family harmony.

Keywords: Adoption, Family, Child. 